had menstruation ever previously been more than a day or two overdue. One of the wemen who miscarried had continued syringing, as she had been wearing a Hodge pessary for some time.)

Of the two cases in which the tubes were shown to be non-patent on insufflation only, patency and good contractions resulted in one case.

Of the four cases in which the tubes were patent only at high pressure and showed no tubal contractions, three subsequently became patent at a lower pressure and showed tubal contractions, but these were good in one instance only.

In two of the cases in which patency resulted and good tubal contractions were obtained examination of the husbands' semen showed a poor spermatozoa count, the semen being below the standard required for successful impregnation.

It will be noted by studying Table I that the cases most likely to respond to treatment were those in which the tubal obstruction was at the fimbriated end.

\section{Treatment of Sterility}

I should like to take this opportunity of reporting the results of sixty-five further cases of lipiodol injection in conjunction with endocrine therapy in the treatment of sterility. In an earlier article (White, 1939) I quoted the results obtained in sixty-two cases. A very legitimate criticism of that investigation was the small number of cases concerned. Table II shows the results of the two groups treated by similar methods, and it will be seen how nearly the figures correspond.

TABLE II.-Results of Lipiodol Injection and Endocrine Therapy in Treatment of Cases of Sterility: Comparison of Two Series of Cases

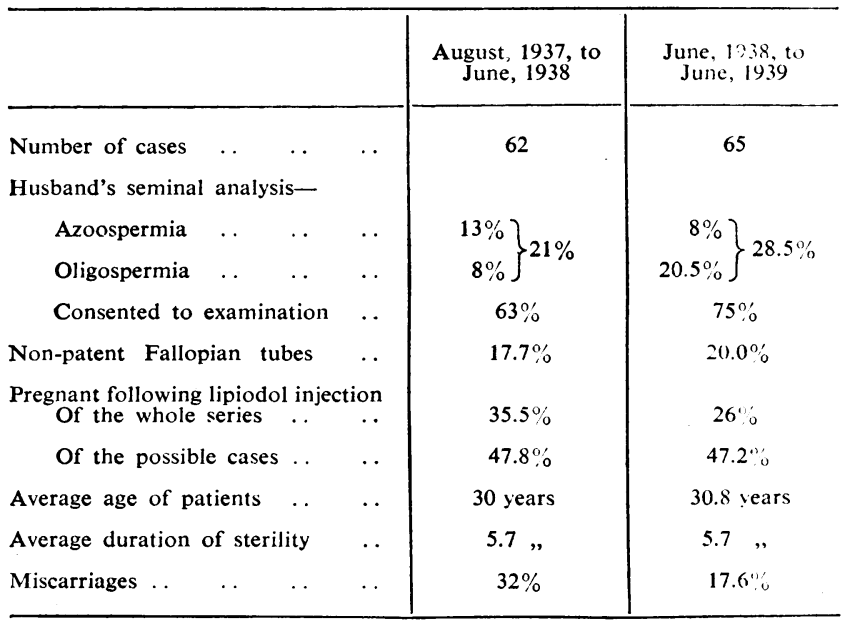

I am much indebted to Miss Dearnley, in whose out-patient department these investigations were carried out.

$$
\text { REIERENCES }
$$

Clauberg, C. (1938). Zbl. Gynïk., 62, 1034.

White, M. M. (1939). British Medical Joturnal, 1, 62

Cancer of Hypopharynx.--The author stresses the impoitance of noting the precise anatomical site, and divides cases for this purpose into "high" and "low." Only in twent:seven "high" cases out of a total of 258 was success obtained by $x$-ray therapy.-- $X$-ray Therapy for Cancers of Hypopharynx. F. Baclesse.-Ann. Oto-laryng., May, 1939, $5,437$.

\section{LATERAL ABERRANT THYROIDS}

BY

\author{
M. ABDUL HAMEED, M.D., M.R.C.P.
}

Professor of Pathology, King George's Medical College, Lucknow, India

Although cases of aberrant thyroids in the neck have been reported from other countries a perusal of the literature has failed to reveal a case from India. It is certain that this condition must have been seen there by others, but owing to the lack of facilities for histological examination it has escaped notice. Only in exceptional cases can a correct pre-operative diagnosis be made: this can only be done by the pathologist. Clinically this complaint is mistaken for tuberculous glands or even for lymphosarcoma, and therefore many such cases remain undiagnosed. It is useful to have the condition in mind when examining a patient with a lump in the neck, because these lumps sometimes become malignant, as in the case here recorded - a fact which naturally alters the prognosis.

A short description of the embryology of the thyroid gland will help in the anatomical conception of these aberrant thyroids in the neck.

\section{Embryology of the Thyroid Gland}

This is a disputed matter. The older embryologists (His and others) thought that the major portion of the thyroid gland, including the isthmus, was derived from a median outgrowth of the epithelium from the floor of the pharynx and that this occasionally persisted as thyroglossal duct. The lateral lobes of the thyroid were supposed to be derived from the lateral out-pocketing of the pharynx (third and fourth branchial clefts), which normally fused with the median anlage. This view was simple enough to explain the presence of aberrant glands

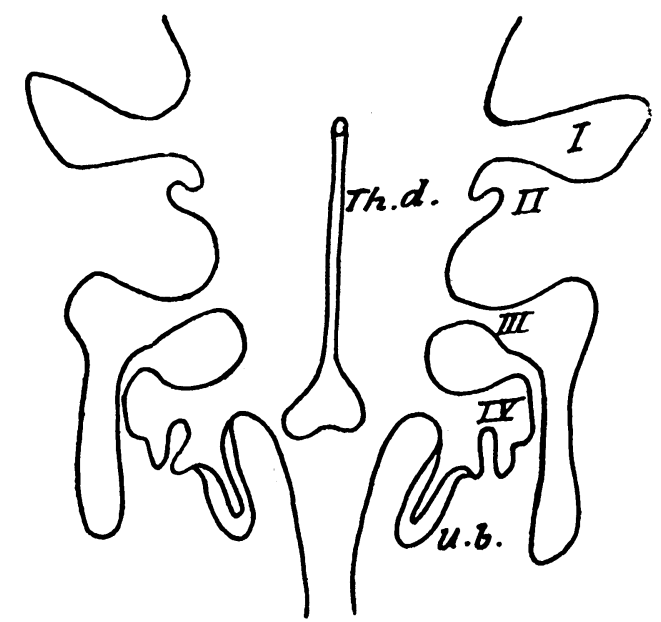

Diagram of the branchial clefts. I, II, III, IV-Lateral clefts. Th.d.-Thyroglossal duct. u.b.-Ultimobranchial body; posterior continuation of pharynx. (After Kaufmann.)

as being due to a failure of the lateral portion to fuse with the median. Since the time of His we have come to know that the third and fourth branchial pouches form parathyroid glands, which differ structurally from thyroid gland, and therefore it was subsequently held that the thyroid gland developed only from the median anlage. Later investigation revealed a developmental relation between the fifth pouch and the thyroid gland. This fifth pouch was called the ultimobranchial body, and Kingsbury has proved that this body is mainly formed by continued growth activity of the posterior portion of the pharyngeal 
pouch. Later it was also found that the ultimobranchial body was capable of producing colloid matter as well. A schematic drawing taken from Kaufmann's (1929) Pathology is reproduced on the opposite page.

It seems possible to account for these aberrant thyroids in the neck as arising from the cells of the posterior portion of the pharynx which, in migration, have failed to fuse with the median thyroid gland, these cells remaining as foetal rests, which subsequently gave rise to tumour formation. Neoplasms of the isthmus of the thyroid are practically unknown, and as these aberrant thyroids can undergo tumour formation (papillary cystadenoma) it is likely, according to Leech et al. (1928), that they are derived embryologically from the same source as the lateral lobes of the thyroid-that is, from the ultimobranchial body.

\section{Case Report}

A man aged 25 had noticed a swelling in the left anterior triangle of the neck six months previously. The swelling extended from the level of the hyoid bone up to the third tracheal ring, the lower end of the swelling reaching a point one inch higher, above the supraclavicular fossa. The middle portion of the swelling was discrete and there was a matted swelling above and below it. The lower pole of this swelling was adherent to the thyroid, which was slightly enlarged, and movable but not hard. The blood picture was normal except for a slight eosinophilia, the basal metabolic rate was normal, and no clinical signs of Graves's disease were observed. The general health of the patient was good. The thyroid gland was slightly enlarged, but there were no enlarged blood vessels running over it and no murmur could be heard there. The lungs were normal and no bone pains of any kind were felt. There was no enlargement of lymph glands in any other part of the body. The urine and blood calcium were normal, and the Wassermann reaction was completely negative. The total leucocyte count was 10,000 per c.mm., with 76 per cent. polymorphs, 18 per cent. lymphocytes, and 6 per cent. eosinophils. No anaemia was present. An operation was performed and the lump in the middle portion of the swelling in the side of the neck was removed first. It had the following characters.

Macroscopic.--It was a pinkish almond-like swelling $1 \frac{1}{2}$ inches by 1 inch, with a few cysts on the surface. The anterior surface showed the presence of coarse trabeculae like a honeycomb, filled sparsely with colloid matter. A definite capsule was present.

Microscopical.-The acini were filled with branching processes. At places they were so packed that the papillary arrangement was lost. Colloid matter was present in less amount. The acini at places contained a little blood. No mitotic figures were present, and there was no lymphoid tissue.

The diagnosis was aberrant thyroid (papillary cystadenoma) with a tendency towards a possible malignancy. After this diagnosis was made the rest of the swelling was removed. These lumps consisted of small glands partially matted together. Macroscopically and microscopically these nodes showed the same appeararce, except that lymphoid tissue was also present in some of them. It was therefore held that metastasis from malignant cystadenoma (aberrant thyroid) had taken place in these lymph glands. A piece from the enlarged thyroid showed a hyperplasia of thyroid tissue and adenomatous changes. There were no mitotic figures, and the blood vessels did not contain epithelial cells. Undoubtedly while these changes were going on in the aberrant thyroid the thyroid gland was also showing hyperplasia.

The patient made an uneventful recovery, and up to a year later had had no recurrence of the disease.

\section{Discussion}

The American statistics show that lateral aberrant thyroids are present only in 0.1 per cent of cases of thyroid disease. The aberrant thyroid gland is mostly found as a single tumour situated in the supraclavicular fossa, but sometimes it may be met with as a chain of glands along the course of the internal jugular vein.

In the above case the aberrant thyroid gland was situated slightly higher than the usual position, as so far described, and the other glandular enlargement in its proximity was not aberrant, but, on the other hand, presented a papillary adenomatous structure in a lymph gland which suggested metastasis. The question may well arise whether the metastasis was derived from the main thyroid gland, which was also enlarged and showed hyperplasia. It could not have been from the thyroid gland, because in that case the metastasis would have been present on both sides. Moreover, metastasis from the thyroid gland is mostly through blood and not through the lymphatics. The main thyroid gland was not nodular, and was also not fixed and did not in any way point towards malignancy.

\section{Summary and Conclusion}

A case of malignant aberrant thyroid with metastasis in the lymph glands is described.

An attempt has been made to describe briefly the embryology of the thyroid gland in relation to the development of aberrant thyroids in the neck.

Attention is drawn to this condition, and the importance of the histological diagnosis is emphasized.

Malignant aberrant thyroid is of low malignancy, and metastasis had taken place only in the local lymph nodes, whereas in adenocarcinoma of the thyroid gland metastasis takes place through blood and may reach any part of the body.

BiBL.IOgRAPHY

Boyd, W. (1938). Text Book of Pathology, Philadelphia

Joll, C. A. (1932) Diseases of the Thyroid, London.

Kaufmann, E (1929). Pathology, London.

Lcech, J. V., Smith, L. W., and Clute, H. M. (1928). Amer. J. Path., 4, 481

\section{Clinical Memoranda}

\section{A Mesenteric Cyst}

The rarity of mesenteric cysts in general and of the enterogenous variety in particular may warrant the recording of the following case.

\section{CASE REPORT}

A well-developed and rather obese single girl aged 17 was seen on December 9, 1939. She complained of pain in the right iliac fossa and of bouts of nausea. The pain, steady and aching in character, had been present for a year, but was getting worse. It was not referred and was unrelieved by postural changes or by heat. The bouts of nausea had been present for a few days. Her appetite was good, her bowels open regularly, and her periods were normal.

On abdominal examination a rounded swelling, tense and ? cystic, about three inches in diameter could be felt in the right lower flank. The swelling had a smooth outline, and appeared to have a slight respiratory excursion. It could be displaced forward from the lower loin, but could not be displaced upward, downward, laterally, or medially. The pelvic organs were normal. A barium meal test revealed nothing abnormal in the caecum or ascending colon, and intravenous pyelography revealed nothing abnormal in the kidney pelves.

A tentative diagnosis of mesenteric cyst was made, and an operation was performed on December 13 through a right 